\title{
Artemídia envolvente: a cianotipia em suas implicações técnicas e funções poéticas
}

PELÓPIDAS CYPRIANO PEL

RICARDO ZANI

Resumo

Este artigo concebe a práxis em artes visuais numa realidade tangencial à elaboração da imagem fotográfica, vislumbrando o signo fotográfico como construtor de conhecimentos e inter-relacionamentos com outros meios e manifestações plásticas, inserindo-o no conceito da fotoescultura. Representa a união da cianotipia, da fotoescultura e da pintura em busca de expressões e poéticas visuais. A cianotipia, que possibilita a fabricação artesanal da emulsão fotográfica, aliada aos processos artemidiáticos, ampliam a aplicação em suportes diferenciados e o jogo de recortes e interferências nesses suportes. As funções poéticas se complementam na envoltória do corpo como um fetiche e um objeto de desejo.

Palavras-chave:

Fotografia, cianotipia, artemídia. 


\title{
Artemídia envolvente: the cyanotype in technical implications and poetics functions
}

\author{
PELÓPIDAS CYPRIANO PEL \\ RICARDO ZANI
}

\section{Abstract}

This article sees the practice in visual arts in a tangential reality the development of the photographic image, viewing the photographic sign as a builder of knowledge and interrelationships with other media and visual manifestations, inserting it into the concept of the tie. It represents the union of cyanotype, photo sculpture and painting in search expressions and visual poetics. The cyanotype that enables artisanal manufacture of photographic emulsion, combined with media art processes extend the application in different media and game clippings and interference in these media. The poetic functions complement the body envelopment as a fetish and an object

Keywords: of desire. 


\title{
Artemidia envolvente: una cianotipia en sus implicaciones técnicas y funciones poéticas
}

\author{
PELÓPIDAS CYPRIANO PEL \\ RICARDO ZANI
}

\section{Resumen}

Este artículo concibe la praxis en artes visuales en una realidad tangencial a la elaboración de la imagen fotográfica, vislumbrando el signo fotográfico como constructor de conocimientos e interrelaciones con otros medios y manifestaciones plásticas, insertándolo en el concepto de de la foto. Representa la unión de la cianotipia, de la fotocultura y de la pintura en busca de expresiones y poéticas visuales. La cianotipia, que posibilita la fabricación artesanal de la emulsión fotográfica, aliada a los procesos artemidiáticos, amplían la aplicación en soportes diferenciados y el juego de recortes e interferencias en esos soportes. Las funciones poéticas se complementan en la envoltura del cuerpo como un fetiche y un objeto de deseo. 


\section{Introdução}

O presente texto tem por finalidade apresentar os conceitos e os resultados encontrados por seus autores ao término do período de estágio de pós-doutoramento do Prof. Dr. Ricardo Zani junto ao Grupo de Pesquisa Artemídia e Videoclip, do Departamento de Artes Plásticas do Instituto de Artes da Universidade Estadual Paulista Júlio de Mesquita Filho UNESP, sob a supervisão do Prof. Dr. Pelópidas Cypriano PEL.

Podemos aferir que um mesmo dispositivo é capaz de desempenhar diferentes papéis de acordo com seu momento histórico. A câmera escura, que até o século XVIII representou um modelo de visualidade clássico e privilegiava uma subjetividade interiorizada e determinista, no século XIX passou a representar um modelo de visão baseado nas incertezas do corpo.

Isso significa dizer que um dispositivo pode sobreviver ao tempo, mas não sem se adaptar aos regimes de visão e de subjetividade de cada época. A pluralidade de dispositivos na atualidade constitui um campo aberto de possibilidades e experimentações, e estas são capazes de produzir transformações na subjetividade humana (CARVALHO, 2011, p. 206).

Portanto, trata-se agora de pensarmos os novos modos de produção da subjetividade a partir dos dispositivos que integram a fotografia ao contexto das novas mídias. Em uma clássica definição, a:

[...] fotografia, ao redimir o barroco, liberou as artes plásticas de sua obsessão pela semelhança [...] Enquanto a fotografia e o cinema são descobertas que satisfazem definitivamente, 
por sua própria essência, a obsessão de realismo [...] A fotografia vem a ser, pois, o acontecimento mais importante da história das artes plásticas. Ao mesmo tempo sua libertação e manifestação plena, a fotografia permitiu à pintura ocidental desembaraçar-se definitivamente da obsessão realista e reencontrar a sua autonomia estética (BAZIN, 1983, p. 124-127).

Na contramão ao preconizado por André Bazin, propomos neste artigo um olhar direcionado à poética fotográfica, não meramente como uma imagem apta a captar toda a realidade a sua volta. Cremos também neste potencial do aparato técnico calcado na perspectiva renascentista, mas cremos, sobretudo, na fotografia como uma linguagem repleta de possibilidades expressivas, portanto plásticas, ao se deixar impregnar das intersecções entre a máquina e o imaginário do Homem, entre a técnica e a arte. Acreditamos que a interação entre as linguagens nos oferece uma gama de opções e nos faz entender que, dentre os questionamentos da arte contemporânea, os processos híbridos incentivam o surgimento e o amadurecimento de uma linguagem pessoal na medida em que "os procedimentos artesanais nele envolvidos fazem com que o fotógrafo deixe de ser um mero agente captador de imagens, ou um mero impressor, para assumir o papel de qualificador da imagem" (MONFORTE, 1997, p. 119).

A quebra de noção de uma representação objetiva e real de sua natureza processual faz com que a fotografia possa ser reconhecida como uma linguagem própria às experimentações estéticas e, quando refletimos sobre as novas possibilidades de ações e criações, nos damos conta de um processo sígnico a representar a construção de realidades fotográficas simbolicamente delineadas por escolhas que objetivam a materialização de intenções, conceitos e poéticas imagéticas que contribuem "[...] para recuperar a antiga idéia grega de téchne, que compreendia tanto a invenção técnica quanto a expressão artística” (MACHADO, 1997, p. 10, grifo do autor).

Para produzir novas categorias, não previstas na concepção do aparelho, seria necessário intervir no plano da própria engenharia do dispositivo, seria preciso reescrever o seu programa, o que quer dizer: penetrar no interior da caixa preta e desvelá-la [...] Numa primeira aproximação, Flusser adverte, portanto, sobre os perigos da atuação puramente externa à caixa preta. Na era da automação, o artista, não sendo capaz ele próprio de inventar o equipamento de que 
necessita ou de (des)programá-lo, queda-se reduzido a um operador de aparelhos, isto é, a um funcionário do sistema produtivo, que não faz outra coisa senão cumprir possibilidades já previstas no programa, sem poder, todavia, no limite desse jogo programado, instaurar novas categorias (MACHADO, 1997, p. 03-04).

Logo, encontramos um vínculo com o pensamento de Rénaud (1989) que, mesmo não deixando de nos esclarecer acerca dos riscos de uma utilização ou manipulação infundada, artificial ou mesmo gratuita das novas tecnologias, crê que nelas habitam "laboratórios experimentais" da sensibilidade humana e de seus pensamentos visuais. Rénaud confia que o emprego ativo e criativo das novas tecnologias não anula as manifestações humanas calcadas nas formas anteriores de expressão, visualidade e materialidade, pelo contrário, a estas são reservadas novas formas de significação e absorção de suas potencialidades expressivas rumo a uma ressignificação da mecânica que as compõem e das relações destas com o fazer artístico (RÉNAUD, 1989). E a pluralidade da fotografia contemporânea faz dela um fenômeno, não uma vertente ou um movimento apenas, mas um momento no qual a flutuação de seus valores encontra-se em sua máxima amplitude e sob diversas óticas (POIVERT, 2015).

As imagens técnicas, ou seja, as representações icônicas mediadas por aparelhos, não podem corresponder a qualquer duplicação inocente do mundo, porque entre elas e o mundo se interpõem transdutores abstratos, os conceitos da formalização científica que informam o funcionamento de máquinas semióticas tais como a câmera fotográfica e o computador (MACHADO, 1997, p. 03).

\section{Arte e tecnologia: a artemídia}

Quando Walter Benjamim (1986, p. 167) notou que mesmo na reprodução mais perfeita havia a ausência de um elemento, "o aqui e agora da obra de arte, sua essência única", este observou que foi na busca por tal essência que se desenrolou toda a história da arte, enquanto o "[...] aqui e agora do original constitui o conteúdo da sua autenticidade" (BENJAMIM, 1986, p. 167). Ao resgatarmos seus apontamentos, o fazemos acreditando numa visão que não aborda uma 
decadência ou degenerescência da arte contemporânea, mas sim, uma mudança em seu estatuto. Se a obra de arte já não pode mais ser pensada em seus termos auráticos originais é porque antes seu valor estava atrelado a um objeto de culto, em que sua própria existência carregava maior importância do que o fato de sua exibição. O tempo nos trouxe a emancipação de seu uso aural, tornando-a mais visível e acessível.

Desde o início dos anos 1980 - e talvez hoje de uma maneira reativada pelas potencialidades dos novos dispositivos digitais - os artistas trabalharam por uma abertura do dispositivo fotográfico, através de mil desregulações, a fim de obter resultados frequentemente inéditos. Trabalhos sobre a própria matéria da imagem, metamorfoses dos espaços, renovação das práticas de montagem atingindo os limites do heteróclito. Essa fotografia, que qualifico voluntariamente pelo termo genérico experimental, marcou por um tempo o caráter inovador da fotografia contemporânea (POIVERT, 2015, p. 139).

Conceitualmente nos inserimos numa discussão filosófica em que a técnica e o automatismo do equipamento fotográfico se prestam aos anseios de uma poética. Neste caso, partir da "[...] filosofia de Flusser seria então uma forma de refletir e discutir sobre as possibilidades de criação e liberdade numa sociedade cada vez mais programada e centralizada pela tecnologia" (MACHADO, 2007, p. 46, grifo do autor). Ademais, a evolução criativa de qualquer objeto artístico está historicamente atrelada aos meios de produção de seu tempo, numa oportuna aproximação entre os conceitos da arte e da mídia nas sociedades de consumo, na qual a arte se apropria de aparatos tecnológicos que, a princípio e em sua origem, não foram pensados como ferramentas e suportes artísticos, tais como a câmera fotográfica. É aí que, para o artista, tais ferramentas não se limitam em meras máquinas para um uso especificamente ao qual foram criadas, subvertendo suas finalidades rumo às produções artísticas e culturais por vezes aleatórias.

Somos, cada vez mais, operadores de rótulos, apertadores de botões, "funcionários" das máquinas, lidamos com situações programadas sem nos darmos conta delas. Pensamos que podemos escolher e, como decorrência disso, nos imaginamos livres e criativos, mas nossa liberdade e capacidade de invenção estão restritas a um 
software, a um conjunto de possibilidades dadas a priori que não podemos dominar inteiramente (MACHADO, 2007, p. 46, grifo do autor).

Ora, às manifestações artísticas não compete transferir para si as qualidades técnicas de tais ferramentas enquanto próprias à produção em larga escala, mas sim, romper com as "[...] normas de trabalho, pelos modos estandardizados de operar e de se relacionar com as máquinas, longe ainda de se deixar seduzir pela festa de efeitos e clichês que atualmente dominam o entretenimento de massa" (MACHADO, 200o, p. 6), rumo a uma reapropriação de tais tecnologias por um viés inovador em proveito de seus ideais poéticos. Seus desafios não estão atrelados a uma defesa inocente das possibilidades técnicas que tais aparatos possam propiciar ao fazer artístico, pelo contrário, as experimentações artemidiáticas devem "[...] traçar uma diferença nítida entre o que é, de um lado, a produção industrial de estímulos agradáveis para as mídias de massa e, de outro, a busca de uma ética e uma estética para a era eletrônica" (MACHADO, 200o, p. 6).

A abordagem que a arte faz dos aparatos tecnológicos contemporâneos "difere significativamente daquela feita por outros setores da sociedade, como a indústria de bens de consumo" (MACHADO, 2007, p. 11), ao nortear-se por liberdades criativas, cercar-se de expressões e sorver-se de poéticas que rompam com certas noções predefinidas, enquanto "[...] a fotografia, o cinema, o vídeo e o computador foram também concebidos e desenvolvidos segundo os mesmos princípios de produtividade e racionalidade, no interior de ambientes industriais e dentro da mesma lógica de expansão capitalista" (MACHADO, 2007, p. 11).

Igualmente, "[...] as artes midiáticas representam a expressão mais avançada da criação artística atual e aquela que melhor exprime sensibilidades e saberes do homem do início do terceiro milênio" (MACHADO, 2007, p. 10), bem como, dentre tantas possibilidades e perspectivas, a do artista "[...] é certamente a mais desviante de todas, uma vez que ela se afasta em tal intensidade do projeto tecnológico originalmente imprimido às máquinas e programas que equivale a uma completa reinvenção dos meios" (MACHADO, 2007, p. 13), imbuindo-se de uma aura criadora que passa ao largo das funções meramente técnicas do aparelho, rompendo incessantemente suas funções ao manuseá-lo numa direção oposta à programação dele. 
Com as formas tradicionais de arte entrando em fase de esgotamento, a confluência da arte com a mídia (ou convergência, segundo Jenkins) representa um campo de possibilidades e de energia criativa que poderá resultar proximamente num salto no conceito e na prática tanto da arte quanto da mídia - se houver, é claro, inteligências e sensibilidades suficientes para extrair frutos dessa nova situação (MACHADO, 2007, p. 27).

\section{A Cianotipia “DIGITAL”}

Feitas as devidas observações, estenderemos agora sobre uma das atividades que foram desenvolvidas durante o estágio de pós-doutoramento, a pesquisa teórico-prática em cianotipia, uma práxis que se estabeleceu numa relação híbrida entre a captura da imagem digital e os procedimentos artesanais da fotografia analógica quando impressa em tecidos, nos permitindo a junção entre a cianotipia e a fotografia digital no resgate de um processo em desuso na fotografia atual, acenando à percepção da existência de uma fotografia que se coloca em oposição à concepção de seu surgimento como um aparato tecnológico a ser utilizado sem que seu usuário tenha a menor noção do que se passa em suas entranhas, num "desconhecimento que se transforma em atividade" (MACHADO, 2007, p. 26).

Ao invés de nos lançarmos num mar de dúvidas quanto às noções que se fazem a respeito do hibridismo, como a que acontece dentro dos ambientes computacionais e suas infinitas possibilidades de interfaces, permitindo com que "[...] muitos realizadores se sintam quase constrangidos a juntar tudo, produzindo resultados que estão mais para a pirotecnia de efeitos do que para a consistência estética e comunicativa do produto" (MACHADO, 2007, p. 78), a hibridização a que nos referimos se relaciona com a convergência dos meios enquanto "[...] processos de intersecção, de transações e de diálogo, implicam movimentos de trânsito e provisoriedade, implicam também as tensões dos elementos híbridos convergidos, partes que se desgarram e não chegam a fundir-se completamente" (MACHADO, 2007, p. 78).

É interessante pensarmos também que a aceitação efetiva da fotografia nos espaços da arte ocorreu com mais evidência no momento em que ela menos se preocupou em responder aos fantasmas históricos que a interrogavam acerca de sua 
legitimidade artística. A fotografia assumidamente híbrida se constituiu numa espécie de linha de frente desse processo de abertura e conscientização, motivando ou produzindo reflexões que nos ajudaram tanto a enfrentar os preconceitos históricos, quanto a reconhecer nas imagens que produzíamos cotidianamente um universo de sentidos menos óbvios. Deixou-se de se definir uma obra a partir do uso tradicional de um determinado aparato ou técnica e, em outras palavras, de se pensar a fotografia apenas a partir do uso de uma câmera, de um suporte fotossensível à luz ou da produção de imagens emolduradas

Em termos de produtividade, a prática da cianotipia nos permite fabricar a emulsão fotográfica artesanalmente e aplicá-la em suportes variados, desde que eles sejam compostos obrigatoriamente de fibras naturais e com ph zero, tais como alguns papéis industriais e os papéis fabricados em casa ou ainda aqueles que sejam pouco "encolados", como os usados para a pintura com aquarelas e que também possibilitam resultados satisfatórios. Da mesma forma, o processo pode ser aplicado em tecidos como o algodão e a seda e, portanto, a cianotipia nos dá a liberdade de utilizar a lonita como suporte. Para sua aplicação é necessária somente a mistura de duas soluções químicas, o citrato férrico amoniacal verde e o ferricianeto de potássio, além de uma fonte qualquer de radiação ultravioleta (UV) eágua. A cianotipia não produz filmes em negativos, mas somente cópias por transferências de contato, sendo sempre necessário que o negativo utilizado seja do mesmo tamanho que a cópia desejada, isto porque o processo com a cianotipia não permite ampliações e nem reduções de tamanho, somente transferências na mesma proporção da imagem original.

A melhor fonte de luz para a exposição de um cianótipo é o sol. Outras fontes de luz bastante adequadas são lâmpadas de quartzo de $1000 \mathrm{~W}$ ou, se disponível, a fonte luminosa a carvão de uma máquina de gravação de chapas de offset. Lâmpadas ultravioletas também podem ser utilizadas. (MONFORTE, 1997, p. 8o-82, grifo do autor).

As duas soluções químicas (citrato férrico amoniacal verde e ferricianeto de potássio) devem ser misturadas em proporções iguais e aplicadas com uma trincha (pincel chato) sobre o suporte (papel ou tecido) a ser sensibilizado. A sensibilização do suporte não precisa ser feita em um local totalmente escuro, porém, deve-se ter cautela com o excesso 
de luz porque a mistura das duas soluções se tornará sensível à radiação UV. Uma vez sensibilizado o suporte, ele deve ser mantido em um local escuro para secar e somente depois de seco deve ser colocado em contato com o negativo para a exposição à luz e a obtenção do resultado final. Historicamente, a cianotipia é um dos primeiros procedimentos de impressão fotográfica descobertos pela humanidade durante o século XIX e seu nome deriva de um dos seus principais componentes químicos, o ferricianeto de potássio, tratando-se de um processo relativamente simples e versátil, sendo sua principal característica visual resultar numa imagem fotográfica em que o seu contraste se dá numa escala tonal de azul, do mais claro ao mais profundo (MONFORTE, 1997, p. 79-83).

Dentre os desafios que encontramos no desenvolvimento de todo o processo, cremos que haja uma consonância dele com questões da área da fotografia que residam nas experimentações constantes entre a manipulação química dos materiais fotossensíveis e suas aplicações em suportes alternativos, bem como na apreensão e consolidação dos procedimentos como normas que atendam à estabilidade no manuseio do método. Como proposta, vislumbramos no exercício das poéticas fotográficas o desenvolvimento das competências e habilidades específicas para o entendimento do que vem a ser a cianotipia. Isto nos dá condições para aprofundarmos as realizações de pesquisas e práticas futuras em busca de vínculos entre a técnica e o conceito, entre o aprendizado e a realização; que os vínculos sejam compatíveis com a realidade mais ampla no contexto da arte e seus fazeres e que, para além da cianotipia, vislumbremos outros processos rumo a "um divisor de águas entre aquilo que é fotografia e aquilo que pode ser chamado de arte fotográfica" (MONFORTE, 1997, p. 119), como a fotoescultura e a fotomontagem.

\section{A exploração do suporte}

Depois de impressas em telas de algodão com dimensões variadas, as imagens fotográficas são modificadas por meio de interferências, como a adição de tinta a óleo ou acrílica, recortes com tesoura e estilete, montagens bidimensionais e sobreposições de tecidos e, por fim, costuras com linha branca que as aproximam daquilo que conhecemos como fotoescultura. $\mathrm{O}$ rompimento do suporte através do tecido rasgado e costurado em partes distintas, a união e a sobreposição de partes dife- 
rentes, a permanência de fendas que possibilitam vazar não somente a estrutura, mas também o corpo ali representado por meio de recortes, quebras e rasgos, nos levam a questionar por sua totalidade. São partes, detalhes ou fragmentos de corpos que não vemos, são "janelas" e confluências de porções de um todo que nos incitam ao imaginário da composição.

Caracterizada como uma expressão multifacetada, que busca através de junções específicas contemplarem os processos de criação, de produção e de uso de materiais inerentes às linguagens artísticas, sobretudo da composição fotográfica inserida em uma montagem escultórica, a fotoescultura deve ser vista como uma imagem fotográfica para além de sua individualidade, de sua singularidade. Devemos enxergá-la em seu conjunto, nas relações entre uma série de imagens que se completam em práticas e exercícios de sensibilidade artística, às vezes, monumental. Nessa perspectiva interdisciplinar podemos caracterizar a fotoescultura como uma prática própria às experimentações artísticas contemporâneas.

Os artistas que criam sob a ótica da fotoescultura abrem, ampliam e propõem que elementos externos à obra participem na discussão de seus processos de criação, concepção, montagem e leitura, nos fornecendo possibilidades ímpares de fruição ao nos permitir um olhar caminhante sobre a obra, lendo-a por fragmentos ou em sua totalidade. Diversas são as formas de apresentação deste dispositivo, desde um álbum ou volume fotográfico que traga uma sequência de imagens que dialogam e impulsionam o receptor a manipulá-lo em busca de uma narrativa, até as montagens mais complexas nas grandes paredes de galerias ou museus. Neste caso, a fotoescultura só adquire um sentido quando o espaço expositivo participa de seu projeto de montagem e interage com a obra, integrando-se a mesma.

Um dos primeiros artistas a desenvolver projetos em fotoescultura foi Christian Boltanski, na década de 1970. Embora em sua obra a bidimensionalidade ainda seja uma premissa, os agrupamentos de imagens por afinidades temáticas propostos por Boltanski sugerem uma organização espacial que leva o receptor a entender a obra em sua totalidade, através de um conjunto de imagens que se completam em seu significado. Em outros casos e na própria obra de Boltanski é a montagem programada das imagens fotográficas e a junção delas com outros materiais, tais como fios, caixas de metal e lâmpadas, que levam o espectador a entender a fotoescultura como uma instalação fotográfica (DUBOIS, 1994, p. 298). 
Depois dele, artistas como o inglês David Hockney e o belga Stefan De Jaeger criaram suas obras com a mesma concepção, a da segmentação e montagem em ladrilhos, assumindo que os fragmentos se completam e indicam a leitura geral do tema. Em certos momentos esses ladrilhos não têm por pretensão perseguir um encaixe perfeito, as formas variam de tamanho e de distância focal, às vezes até o ponto de vista é alternado, criando uma obra com vistas frontais e laterais, variando seus ângulos de tomada e privilegiando formas descontínuas iguais a uma composição cubista.

Em outros dois casos, os artistas Pierre Boogaerts (Bélgica) e Jan Dibbets (Holanda) levaram a noção do agrupamento fotográfico às grandes proporções. Boogaerts trabalhou com séries de fotografias feitas sobre o céu de Nova Iorque, variando seu ângulo de visão das extremidades dos arranha-céus posicionados em calçadas opostas e tendo o céu entre eles como o elemento central da composição, chegando a abranger ângulos de visões maiores de $90^{\circ}$ entre as extremidades da obra. Boogaerts criou obras em formas de grandes colunas nas paredes das galerias a partir de fragmentos em médio formato, privilegiando a verticalidade e descartando a necessidade de coerência e exatidão no encontro entre as peças, a linearidade aqui não mantinha uma ordem formal (DUBOIS, 1994, p. 297).

Jan Dibbets seguiu o mesmo caminho de Boogaerts, porém, em suas obras é a horizontalidade dos painéis que impera através de suas Paisagens Panorâmicas realizadas a partir dos anos 1970. As obras de Dibbets propõem encaixes rigorosos entre seus fragmentos e por vezes algumas peças têm suas formas completadas com interferências de desenhos feitos pelo próprio artista, transmitindo continuidade às formas arquitetônicas.
Obsessão n. 13. Autor: Ricardo Zani (2012). Técnica: cianotipia sobre tela, linha branca e tinta a óleo. Dimensões: $36 \times 102 \mathrm{~cm}$.

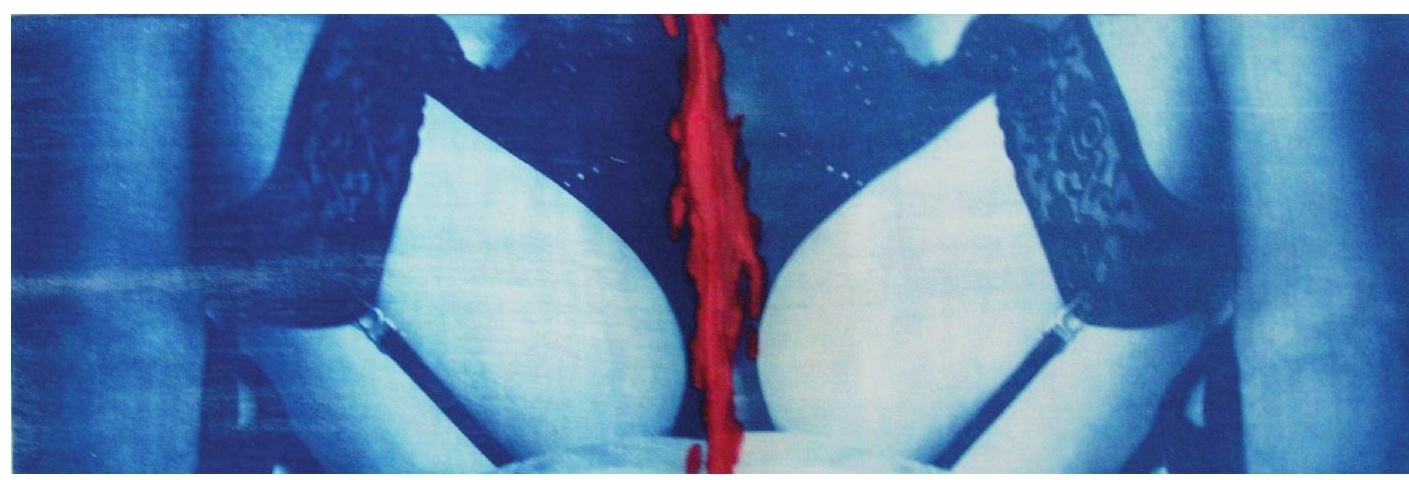


Obsessão n. 19. Autor: Ricardo Zani (2013). Técnica: Cianotipia sobre tela e tinta acrílica. Dimensões: tríptico de $45 \times 220 \mathrm{~cm}$.
O que está em jogo nesta relação entre a fotografia e a escultura é a noção de volume que nos é dada pelo formato do suporte, por seu resultado final diante da montagem apresentada e não simplesmente por sua sugestiva representação imagética calcada na perspectiva renascentista. A fotoescultura conduz o espectador a questionar e a variar o ponto de vista único e central de fruição de uma obra, como nos explica Philippe Dubois:

[...] trata-se de considerar a foto aqui não apenas como uma imagem, mas também (e às vezes, sobretudo) como um objeto, uma realidade física que pode ser tridimensional, que tem consistência, densidade, matéria, volume. Em suma, que pode ser encarada igualmente como uma escultura.

Acontece de essas esculturas fotográficas adquirirem uma forma relativamente elaborada, em que a estratégia da situação revela efeitos, às vezes, bastante sofisticados e, com isso, a interpelação dela pelo espectador pode se fazer de forma ainda mais intensa.

[...] O primeiro exemplo são os mosaicos de polaróide do belga Stefan De Jaeger (ou, mesmo espírito, as Piscinas de papel e outros agrupamentos "cubistas" de David Hockney) [...] O efeito de ladrilhagem é imediato (DUBOIS, 1994, p. 292-294, grifo nosso).
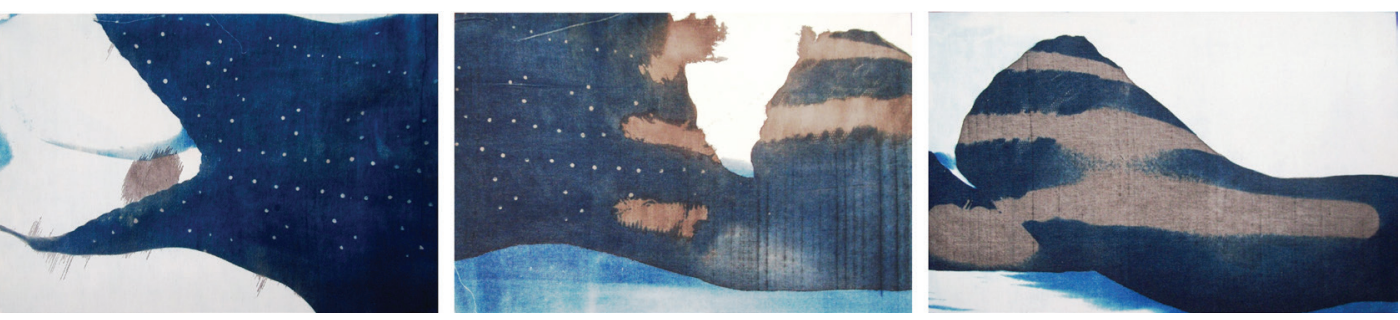

A arte contemporânea flerta com o hibridismo estético e estabelece uma relação forte com certas impregnâncias do passado, ressignificando temas e suportes numa articulação com o presente. Por tal razão, as telas de algodão que foram utilizadas no desenvolvimento das práxis relacionadas ao estágio de pós-doutoramento possuem proporções variadas e assimilam interferências diversas. Como estruturas a suportar (fixar) as telas de algodão foram utilizadas chassis de madeira ou placas de compensado, o que nos permite ainda "brincar" 
com a ideia de um quebra-cabeça fotoescultórico a unir todas as partes fragmentadas de um tema numa imagem única e maior.

\section{O corpo feminino e seus adereços}

Meias de seda envolvendo pernas bem torneadas sempre nos causaram fascínio e não nos recordamos exatamente de quando isso começou, provavelmente, porém, seja um resquício de nosso imaginário ou vivência infantil. Entretanto, já na vida adulta nos recordamos com perfeição de alguns filmes e atrizes que aguçaram o nosso gosto e prazer por esta indumentária feminina, podendo nos referir com precisão ao cineasta espanhol Luis Buñuel e aos seus filmes Ensaio de um Crime (1955) e Simão do Deserto (1962). Nestas obras acreditamos ter encontrado os mais belos pares de coxas cobertos por meias de seda negras que o cinema já pôde criar. Por serem ainda obras filmadas em películas $\mathrm{PB}$, o contraste das meias negras em pernas tão alvas nos chamaram mais a atenção. No primeiro filme uma mulher aparece indefesa e suas coxas são cobiçadas pelo olhar masculino, mesmo sendo o de um garoto pretensamente inocente. No segundo, é a mulher que usa e abusa de seus atributos físicos como arma para seduzir um beato convicto. Em ambos, tais objetos se configuram em metáforas do desejo.

O erotismo aparece, os fantasmas e as pulsões desencadeiam-se quando a roupa é apenas um todo com o corpo. Quando a carne e o tecido se misturam ou confundem. Quando os pescoços, os ombros, os braços, as coxas são da mesma textura da seda, do veludo ou do vinil, quando as fendas do tecido parecem entrelaçar-se nos sulcos da pele. Por outras palavras, 65 por cento dos indivíduos "normais" do sexo masculino têm tendências fetichistas. Se a cinta de ligas, invenção recente, da idade da Torre Eiffel, é, ainda hoje, a mais nobre conquista erótica do Ocidente, ela tem antepassados ilustres (NÉRET, 1994, p. 14-16-21).

Transportando essa simbologia para o signo fotográfico e às imagens que foram produzidas nas práxis de pós-doutoramento, acreditamos que as meias de seda, os sapatos ou botas de salto alto, além dos demais adereços femininos que compõem as cenas são, na verdade, o motivo principal à re- 
alização dessas cenas. Podemos reconhecer que o que está em evidência são as vestes da mulher e não exatamente o seu corpo, o destaque, aqui, recai sobre aquilo que o cobre. Por ser este fetiche calcado em determinados utensílios da indumentária feminina a vestir a modelo, não há uma busca por imagens que traduzam um desejo pelo corpo, mas sim, um desejo pela forma como o corpo se apresenta coberto de adereços sensuais, transformando essa mulher desconhecida em um grande enigma.

Além de referenciadas na fotoescultura, algumas imagens incorporam certas influências das obras do escritor francês Marquês de Sade (A filosofia na alcova - os preceptores imorais) e de Luis Buñuel ( $O$ alucinado, Esse obscuro objeto do desejo e outros), que por sua vez também buscou em Sade inspiração para a criação dos seus roteiros. Trata-se de uma ideia fixa desses autores em se costurar a vagina, sugestiva e simbolicamente representadas aqui pelas costuras em partes distintas das imagens e, por tal razão, a série de imagens desenvolvida nessas práxis se chama Obsessão. Com relação ao tema, a representação e a (re)significação do corpo humano são uma constante em nossos trabalhos, sejam eles práticos ou teóricos, o corpo é um objeto de estudo (e desejo) que não se altera com o tempo e que continua presente em imagens produzidas a partir de um mesmo conceito, criando-se uma identidade entre eles.

\section{Considerações finais}

Sabendo que a montagem arquitetônica da fotografia em mosaicos e sua relação com o espaço expositivo nos transmitem o efeito de fotoescultura, conhecendo as obras de Christian Boltanski, David Hockney, Pierre Boogaerts e outros, e debruçando-nos sobre a produção destes artistas que criaram sob a ótica da fotoescultura é que nos propusemos ao desenvolvimento de uma atividade que ao mesmo tempo conciliasse questões intelectuais e artísticas no âmbito da fotografia, numa pesquisa teórico-prática em cianotipia que nos permitisse não somente experimentações constantes relacionadas às manipulações químicas dos materiais fotossensíveis, como também suas aplicações em suportes alternativos.

Em se tratando da fotografia na contemporaneidade, percebemos que há um amplo cenário de miscigenações e mediações que abarcam questões refletidas em nosso processo fotográfico. Uma das principais indagações reside indubita- 
velmente na direção das hibridizações dos dispositivos imagéticos e da experiência visual. Notadamente, as modalidades de fotografia apresentadas sobre o contexto das novas mídias promovem uma reorganização não apenas na essência do que foi fundado como o fotográfico, mas também em relação ao observador em contato com certas formas de produção de imagem, vendo-se obrigado a fazer novos questionamentos acerca de valores estéticos anteriormente adquiridos em vista, não do reconhecimento da imagem, mas da própria experiência imagética.

Embasados nas novas possibilidades de ações que contemplam o desenvolvimento de competências e habilidades específicas da fotografia em sua relação com as artes visuais, como a pesquisa de suportes, a junção dos meios analógicos com os digitais e, ainda, às experimentações de materiais diversos, foi que visamos estabelecer durante o estágio de pós-doutoramento, estudos artísticos que articulassem a percepção do espaço como prática e forma mais elaboradas destas manifestações.

\section{Referências}

BAZIN, André. Ontologia da imagem fotográfica. In: XAVIER, Ismail. (Org.). A experiência do cinema - antologia. Tradução Teresa Machado. Rio de Janeiro: Edições Graal/ Embrafilme, 1983. p. 121-128. (Coleção Arte e Cultura).

BENJAMIN, Walter. A obra de arte na era de sua reprodutibilidade técnica. In: Obras escolhidas. 2. ed. São Paulo: Brasiliense, 1986.

CARVALHO, Victa. Cotidiano e experiência na fotografia contemporânea. Em Questão, Porto Alegre, v.17, n. 1, jan./ jun. 2011.

DUBOIS, Philippe. O ato fotográfico e outros ensaios. Tradução Marina Appenzeller. Campinas: Papirus, 1994.

MACHADO, Arlindo. A fotografia como expressão do conceito. Revista Studium, Campinas, UNICAMP, n. 02, 2000. Disponível em: <www.studium.iar.unicamp.br $>$.. Acesso em: maio 2004. . Arte e mídia. Rio de Janeiro: Zahar, 2007. Repensando Flusser e as imagens técnicas. In: ARTE EN LA ERA ELECTRÓNICA - perspectivas de una nueva estética, 1997, Barcelona. Barcelona: Centre de Cultura Contemporania de Barcelona, de 29 de janeiro a or de fe- 
vereiro de 1997.

MONFORTE, Luiz Guimarães. Fotografia pensante. São Paulo: SENAC, 1997.

NÉRET, Gilles. Arte erótica. Alemanha: Taschen, 1994.

POIVERT, Michel. A fotografia contemporânea tem uma história? Palíndromo, Florianópolis, n. 13, jan./jun. 2015. Tradução Andrea Eichenberger..

RÉNAUD, Alain. Pensare l'immagine oggi: nuove immagini, nuovo regime del visibile, nuovo immaginario. In: V.A., Videoculture di fine secolo. Napoli: Liguori, 1989. p. 11-27.

SANTOS, Alexandre; SANTOS, Maria Ivone dos. (Org.). A fotografia nos procedimentos artísticos contemporâneos. Porto Alegre: Unidade Editorial da Secretaria Municipal da Cultura, UFRGS, 2004.

Recebido em: 27/05/2016

Aceito em: 10/04/2017

\section{PELÓPIDAS CYPRIANO PEL.}

pel@ia.unesp.br.

Professor adjunto (livre-docente) no Instituto de Artes da Universidade Estadual Paulista Júlio de Mesquita Filho - UNESP. Cineasta com experiência na interface Comunicação-Arte-Ciência, com ênfase em cinema. É avaliador institucional e de cursos do SINAES e do CEE, com atuação em EAD. Líder do Grupo de Pesquisa Artemídia e Videoclip.

\section{RICARDO ZANI}

zani@ifsp.edu.br.

Docente em Artes no Instituto Federal de Educação, Ciência e Tecnologia de São Paulo - IFSP, campus Salto. Artista visual com experiência nas interrelações entre as estéticas e teorias audiovisuais, fotografia, surrealismo e intertextualidade. Possui Bacharelado em Artes Plásticas pela Universidade Estadual Paulista Júlio de Mesquita Filho - UNESP (1997), Mestrado em Multimeios (2001) e Doutorado em Artes (2010) pela Universidade Estadual de Campinas - UNICAMP, e Pós-Doutorado (2014) pelo Departamento de Artes Plásticas do Instituto de Artes da Universidade Estadual Paulista Júlio de Mesquita Filho - UNESP. É avaliador institucional e de cursos do SINAES e do CEE. Membro do Grupo de Pesquisa Artemídia e Videoclip. Endereço. Rua Praia de Ipanema, 762, Sol d'Icaraí, Salto/SP, Cep. 13.327-130. 